\title{
The Prostatic Molecular History in Carcinogenesis-Therapy Resistance
}

\author{
Lawrence M Agius* \\ Department of pathology, University of Malta Medical School, Malta
}

Submission: September 27, 2018; Published: October 09, 2018

"Correspondence Address: Lawrence M Agius, Department of pathology, University of Malta Medical School, Mater Dei Hospital Msida, TAL- QROQQ Malta, Europe, Tel: 356-21451752; Email: lawrence.agius@um.edu.mt

\begin{abstract}
The dynamics of interactivity of substantial biochemical reactivity patterns of androgen-independent action is induced in terms of onset and progression as evidenced in many castration-resistant instances of prostate cancer. Variable response elements to androgens in the genome allow for the DNA-binding portion of the androgen receptor (AR) to evolve in terms of its transcriptional functions as well evidenced by splicing of the androgen receptor pre-messenger RNA moieties. It is relative to the evolving gonadal and adrenal androgen output that a clear definition of resistant states of metastatic prostatic cancer includes also the permissive development of mutations as additional variable parameters in oncogene dysfunctionality.
\end{abstract}

\section{Introduction}

The evolving dimensions for spread of castration-resistant prostatic cancer include definitions for further biochemical dimensionality in serial interactivities of the AR.The genome of the cancer cell arises from the prostatic epithelium and is further reflected by paracrine or intracrine events in carcinogenesis. The role for anti-inflammatory macrophages in the progression of primary prostate cancer is well established but little is known about macrophages in the context of metastatic prostate cancer to bone [1]. The differential attributes for substantial carcinogens include the dimensional scope for further carcinogenesis as pseudo-evolutionary attributes. This is borne out by the scope for eradication of the primary and metastatic deposits of prostate cancer. B lymphoma Moloney murine leukaemia virus insertion region 1 (BMI1) predicts drug resistance, tumor recurrence, and eventual therapy failure of a number of cancer subtypes; it is an oncogenic and epigenetic regulator in the initiation of tumorigenesis, progression and relapse of prostate cancer [2]. With time, an increase in number and severity of genomic alterations adds molecular complexity and is associated with progression to metastatic prostatic cancer [3]. Deletions or mutations in PTEN and TP53 tumor suppressor genes are linked to lineage plasticity in therapy-resistant prostate cancer [4].

\section{Promiscuity}

Promiscuity of events in binding dynamics of the AR molecule is specific distributional realization as further projected in terms of ongoing further evolutionary history in carcinogenesis.Loss of functional nucleoside transporters is associated with reduced efficacy of antimetabolites and their derivates and treatment failure in diverse malignant neoplasms [5]. Performance attributes are androgen-resistance as further systems of cooperative dimensionality. This is evidenced by the invariable reconstitution of events of ligand-induced transactivation by the AR molecule. MMP7 serum levels help select castration resistant prostate cancer patients likely to benefit from docetaxel chemotherapy [6]. Distributional reappraisal includes the genomic and also non-genomic actions of the activated AR molecule.Constitutive reactivation of the AR-ligand complex includes further distributional increment in the evolutionary systems of operative effectiveness of androgens as oncogene in prostatic cancer and also as suppressor functionality in breast carcinogenesis.In such terms, immediate delivery events further compromise the realization of sequential response elements in the nuclear DNA, as further proposed by splice events in molecular history.

\section{Distributional Hierarchy}

Distributional hierarchical re-organization attributes the systems of effective response in terms that herald the emergence of androgen-resistance of prostate cancer cells.Taxans are widely employed for advanced prostate cancer and interact with beta-tubulin to trigger cell cycle arrest and apoptosis [7]. The incremental re-distribution of substantial patterns of hard-wired signaling pathways in prostatic carcinogenesis permit the eventual adaptation of the cancer cells to further involve dimensions of genomic damage consequence. Epithelial-to-mesenchymal transition involves enhanced expression of proteolytic enzymes, 


\section{Cancer Therapy \& Oncology International Journal}

integrins, cytoskeletal rearrangements and can be studied in the transwell migration assay [8].

\section{System Profiles}

Emergence of system profiles for prostate cancer resistance to androgens as further proposed is a system preference that allows for the re-definition of genomic damage. This further conforms to dimensions of re-distribution of androgen response elements. Constitutive activation of injury is performance-geared in a manner that is dictated by evolutionary dimensions of responseindependent activity and reactivity.The suboptimal efficacy of bevacizumab may relate to molecular events triggered during prostate cancer progression [9].

It is within the performance status of a carcinogenesis phenomenon that the full biochemical profile of androgeninduced action includes the performance of a variability that emerges as differential hormonal response profiles. The role of CD133 as a cancer stem cell marker is useful in demonstrating therapy-resistant populations with stem-like features as distinct subpopulations of malignant cells residing within parental cell lines [10].Incremental integers are systematic approach to the ensuing intra-crine and para-crine events that re-distribute the contractual performance of recognizable events in hormonal reconstitution of the prostatic epithelial cells.Castration-resistant prostate cancer is characterised by reactivation of androgen receptor signaling in part by increased expression of AR splice variants [11]. Dimensional re-characterization of genomic damage is further compounded by the emergence of nuclear/cytoplasmic interaction that includes the interface surface of the DNA-binding domain of the androgen receptor. Inclusive dynamics are further proposed as defining link within the systems of operative response that in turn evolves as constitutional autonomy within definitions of the prostatic carcinogenesis process.

\section{Cell Signaling}

Cell signaling promotions are system preferences in the emergence of such variable indices as AR mutations and as splice variants in carcinogenesis.Patterns in such cell signaling is attribute re-distribution that is dictated by the further conformational adaptability of such systems as proliferation, differentiation and various other biologic re-activities.These include dimensions of recognition of the genome of its own damaged status.The parameters of response as constitutional reappraisal are projected status for the emergence of evolutionary adaptation to further genomic damage. LSD1 inhibition attenuates androgen receptor V7 splice variant activation in castration resistant prostate cancer models [12].Therapeutic inhibition of androgen signaling may promote castrate resistance by inhibiting tumor suppressive functions of the androgen receptor [13].

\section{Proposed Adaptational Diversity}

Proposed diversity is a cardinal image status that allows for permissive adaptation within the realized castration-resistance of metastatic prostatic cancer, as well evidenced by systems performance of cell-signaling pathways. It is significant to consider parameter conformation within the performance indices for further adaptation as the evolutionary cascades of response and non-response to the ligand-bound androgen receptor.Incremental sensitivity and autonomous response are examples for further change that is dimensionally reconstituted as fixed and also hyper-variable indices for adaptation to a diversified hormonal micro-environment. The TP53-MDM2-AR-AKT crosstalk, which plays a critical role in prostate carcinogenesis, is regulated by the deubiquitinating enzyme USP12 in prostate cancer [14].

\section{Inclusive Dimensions}

Inclusive attributes for system preference overlap with the proposed castration-resistance in terms that include the dimensionality of the genomic damage. This is further redefined by permissive re-allocation of injury to a genomic DNA undergoing damage-repair.In such terms, the overall or global performance attributes of androgen characterization include the distributional pattern as dictated by a whole series of adaptive processes of reconstitution. Cancer stem cells are considered the root of therapy resistance, relapse and metastasis, and should lead to development of novel immunologic approaches targeting cancer stem cells [15].

Significant substantiation is further projected as overall re-characterization of preference options in adaptability and response as indeed possible by permissive events in optiondominant systems of response-effect. Identification of new biomarkers and therapeutic targets may allow personalisation of castration-resistant prostatic cancer therapy, as for example phosphoproteomics that enable the analysis of signaling networks in individual tumors [16].

Profile of genomic damage is an over-reaching series of events that may account for androgen-resistance in prostatic carcinogenesis.It appears that elF4E phosphorylation enhances the rate of translation in promoting resistance of oncogene mRNAs to increase tumorigenicity [17]. Inclusive phenomena allow for the further re-definition of genomic damage within scopes of redistribution, as well evidenced by the performance of hard-wired signaling pathways attributed to the androgen receptor in the normal prostatic epithelial cells.In such terms, ongoing injury to the genome is requisite dimension for projected permissiveness that evolves within the phenomena of carcinogenesis. A novel strategy is the combination of radiation and CD105 targeting to address the DNA repair and metabolic addiction induced by irradiation in p53-functional prostate cancers [18].

\section{Permissivity}

Permissive micro-environments allow for the recognition of genomic damage that substantially promotes injury within confined terms of evolutionary adaptation, as indeed projected by chemotherapy and adjunctive forms of attempted formulation in cancer therapy.Formation of the androgen receptor splicing 
variant 7 is one of the major mechanisms by which resistance of prostate cancer develops in androgen deprivation therapy [19]. The re-distributional hierarchy is further defined by systems of response that in turn characterize variable signaling pathways.

\section{Conclusion}

Evolutionary status for permissiveness in carcinogenesis is performance index for parameter re-formulation in prostatic carcinogenesis that in turn is castration-resistant.Ligand-bound androgen receptors conform to a nuclear/cytoplasmic interface in the manner of inclusive dynamics that re-distribute potential damage to the epithelial cell genome in a manner that is permissive and adaptive.

The proponents for substantial cancer resistance to adjuvant therapy are appraised dimension for the continuing evolutionary history of a specific lesion within scopes for further transformation. The performance status is serial conformational reappraisal for continued response in the face of a non-effective series of signaling pathways that constitute adaptive change.Increments for such transformation are central to the understanding of a carcinogenesis phenomenon within the ever-evolving adaptation to the genomic damage of the epithelial cells lining prostatic glands. Re-emergence profiles include castration resistance that is progressively enhanced by such genomic injury and performance. Attributes for re-definition include the realization of performance indices as parameters in their own right that dictate in strict terms the phenomenon of increased autonomy in cellular proliferation and differentiation.

\section{References}

1. Lo CH, Lynch CC (2018) Multifaceted roles for macrophages in prostate cancer skeletal metastasis. Front Endocrine (Lausanne) 9: 247.

2. Liu Q Li Q, Zhu S, Yi Y, Cao Q (2018) B lymphoma Moloney murine leukemia virus insertion region 1: an oncogenic mediator in prostate cancer. Asian J Androl.

3. Arora K, Barbieri CE (2018) Molecular subtypes of prostate cancer. Curr Oncol Rep 20(8): 58.

4. Blee AM, He Y, Yang Y, Ye Z, Yan Y, et al. (2018) TMPRSS2-ERG controls luminal epithelial lineage and antiandrogen sensitivity in PTEN and TP53-mutated prostate cancer. Clin Cancer Res 24(18): 4551-4565.

5. Drapela S, Fedr R, Khirsariya P, Paruch K, Svoboda M, et al. (2018) Flow cytometric analysis of nucleoside transporters activity in chemoresistant prostate cancer model. Klin Onkol 2018(1): 140-144.
6. Szarvas T, Sevcenco S, Modos O, Keresztes D, Nyirady P, et al. (2018) MMP-7, sFAS and FasL serum levels for predicting docetaxel resistance and survival in castration-resistant prostate cancer. BJU 122(4): 695704.

7. Luz Flores M, Saez C (2018) Protocols for the study of taxanes chemosensitivity in prostate cancer. Methods Mol Biol 1786: 153-173.

8. Van de Merbel AF, van der Horst G, Buijs JT, van der Pluijm G (2018) Protocols for migration and invasion studies in prostate cancer. Methods Mol Biol 1786: 67-79.

9. Cereda V, Formica V, Roselli M (2018) Issues and promises of bevacizumab in prostate cancer treatment. Expert Opin Biol There 18(6): 707-717.

10. Kanwal R, Shukla S, Walker E, Gupta S (2018) Acquisition of tumorigenic potential and therapeutic resistance in CD133+ subpopulation of prostate cancer cells exhibiting stem-cell like characteristics" Cancer Lett 430: 25-33.

11. Moses MA, Kim YS, Rivera-Marquez GM, Oshima N, Watson MJ, et al. (2018) Targeting the Hsp40/Hsp70 chaperone axis as a novel strategy to treat castration-resistant prostate cancer. Cancer Res 78(14): 40224035.

12. Refuge da Mota S, Bailey S, Strivens RA, Hayden AL, Douglas LR, et al. (2018) LSD1 inhibition attenuates androgen receptor V7 splice variant activation in castration resistant prostate cancer models. Cancer Cell Int 18: 71

13. Huang PA, Price DK, Figg WD (2018) Molecular drivers of metastatic castrate-resistant prostate cancer: new roads to resistance. Cancer Biol There 14: 1-2.

14. McClug UL, Chit NCTH, Azizyan M, Edwards J, Nabbi A, Riabowol KT, et al. (2018) Molecular mechanism of the TP53-MDM2-AR-AKT singling network regulation by USP12. Oncogene 9(38): 24992-25007.

15.Zhang D, Tang DG, Rycaj K (2018) Cancer stem cells: regulation programs, immunological properties and immunotherapy. Semin Cancer Biol 52(Pt 2): 94-106.

16. Yang W, Freeman MR, Kyprianou N (2018) Personalization of prostate cancer therapy through phosphoproteomics. Nat Rev Urol 15(8): 483497.

17. D’Abronzo LS, Ghosh PM (2018) elF4E phosphorylation in prostate cancer. Neoplasia 20(6): 563-583.

18. Madhav A, Andres A, Duong F, Mishra R, Haldar S, et al. (2018) Antagonizing CD105 enhances radiation sensitivity in prostate cancer. Oncogene 37: 4385-4397.

19. Fan L, Zhang F, Xu S, Cui X, Hussain A, et al. (2018) Histone demethylase JMJD1A promotes alternative splicing of AR variant 7 (AR-V7) in prostate cancer cells. Proc Natl Acad Sci USA 115(20): E4584-E4593. 
This work is licensed under Creative Commons Attribution 4.0 License

DOI: 10.19080/CTOIJ.2018.12.555838
Your next submission with Juniper Publishers will reach you the below assets

- Quality Editorial service

- Swift Peer Review

- Reprints availability

- E-prints Service

- Manuscript Podcast for convenient understanding

- Global attainment for your research

- Manuscript accessibility in different formats ( Pdf, E-pub, Full Text, Audio)

- Unceasing customer service

Track the below URL for one-step submission https://juniperpublishers.com/online-submission.php 